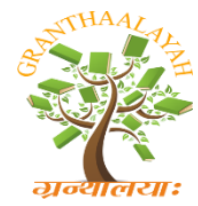

INTERNATIONAL JOURNAL OF RESEARCH GRANTHAALAYAH A knowledge Repository

Science

\title{
MICROWAVE TRAVELLING WAVE TUBE - A SUMMARY OF AN ANALYTICAL, NUMERICAL AND EXPERIMENTAL THERMAL ANALYSIS
}

\author{
Artur Wymysłowski ${ }^{* 1}$, Waldemar Wiejak ${ }^{2}$, Piotr Słupski ${ }^{1,2}$ \\ ${ }^{* 1}$ Wroclaw University of Science and Technology, ul. Janiszewskiego 11/17, 50-372 Wroclaw, \\ Poland \\ ${ }^{2}$ PIT-RADWAR S.A., ul. Krakowska 64, 50-425 Wroclaw, Poland \\ DOI: https://doi.org/10.29121/granthaalayah.v5.i6.2017.2042
}

\begin{abstract}
Travelling Wave Tube (TWT) is an electronic vacuum microwave device, which is used as a high power microwave amplifier, mainly in telecommunication purposes and radar systems. TWT's seem to be an alternative and a more reliable solution than semiconductor devices when building high power and high frequency applications. Thermal behaviour of TWT is one of the key aspects influencing its reliability and working parameters. In fact, the standard TWT is treated as a high power device and the supplied power is dissipated mainly through conduction and convection phenomena. In practical applications, depending on a type of TWT, they can be cooled either by a forced liquid or air circulation. The main goal of the presented research was to perform analytical, experimental and numerical analysis of temperature distribution of a low band TWT in case of a typical working condition. Because theoretical analysis seems to be very complex, thus it was decided to support it with experimental measurements and numerical simulations as well as with the simplified analytical formulas. As a first step of the presented research, the analytical analysis and numerical modelling of the helix TWT was carried out. The objective of the thermal analysis was to assess the temperature distribution in different parts of the helix TWT assembly during extreme standard and working conditions. Afterwards, the obtained numerical results were validated by experimental measurements, which were carried out using a custom designed TWT test sample and corresponding experimental measurement tools.
\end{abstract}

Keywords: Travelling Wave Tube; Microwaves; Heat Dissipation; Analytical Analysis; Numerical Modeling; Experimental Measurements.

Cite This Article: Artur Wymysłowski, Waldemar Wiejak, and Piotr Słupski. (2017). "MICROWAVE TRAVELLING WAVE TUBE - A SUMMARY OF AN ANALYTICAL, NUMERICAL AND EXPERIMENTAL THERMAL ANALYSIS." International Journal of Research - Granthaalayah, 5(6), 353-361. 10.29121/granthaalayah.v5.i6.2017.2042. 


\section{Introduction}

Travelling Wave Tube (TWT) is an electronic vacuum microwave device, which is used as a high power microwave amplifier, mainly for telecommunication purposes, as a driver or output tube in advanced radar systems and electronic test equipment. TWTs seem to be an alternative for semiconductor devices and in fact more reliable solution, mainly for high power and high frequency applications. The typical operating frequency range of a helix TWT would be from 1 $\mathrm{GHz}$ to over $5 \mathrm{GHz}$, where each tube delivering a peak output power in a fixed frequency range. There are a number of different constructions of TWT devices, of which the so-called helix TWT is the most popular [1,2]. Thermal behavior of a TWT is one of the key aspects influencing its reliability and working parameters. In fact the standard TWT is treated as a high power device and the supplied power is dissipated mainly through conduction and convection phenomena while the heat dissipation through the radiation can be neglected. In practical applications, depending on a type of TWT, they can be cooled either by a forced liquid or air circulation. Additionally, in some special TWT types, they would require mixed air-liquid cooling or specially designed heat conduction to the device base [3].

The main goal of the research was to perform a combined experimental, analytical and numerical analysis of a temperature distribution of a low band TWT in case of a typical working condition. Because the theoretical analysis seems to be very complex thus it was decided to compare the experimental results with the numerical simulations as well as with the simplified analytical formulas. One of the advantages of numerical simulations over the analytical formulas is the ability to include real geometry and boundary conditions without a need of any physical phenomena simplification or neglecting any geometrical details. On the other hand the numerical analysis in comparison to experimental one, allows for application of an advanced numerical optimization algorithms, which makes it a very practical engineering tool during the prototyping stage. As a first step of the presented research, the analytical analysis and numerical modeling of the helix TWT was carried out. As a final stage of the research the achieved results were validated by the experimental measurements, which were carried out using a specially designed TWT test samples and corresponding experimental measurement setup [4].

\section{State-of-the-Art}

Currently, TWTs are used as an electronic vacuum microwave power source technology for radar, satellite communication, particle accelerators, industrial processes and military applications amongst others [5,9], being quoted as six times better than an equivalent solid state device [9]. After profound tests of semiconductor devices for space, since 1995 the cosmic industry has returned to using vacuum devices. The first vacuum tubes, e.g.: the vacuum diode by John Ambrose Fleming (patent from 1901) or the triode by Lee De Forest (1906) are products developed over a century ago [6]. The technology leapfrog, usually assigned to semiconductor or software industries has also reached the power microwave electronics industry, with the requirements for high vacuum, exceptional mechanical and thermal properties and durability. As one can imagine, it could require significant effort to replace broken satellite communications chips, thus the currently available lifetimes of vacuum products range up to several millions of hours [1], with the costs spanning a wide range of between hundreds to hundreds of thousands of dollars per piece. The invention of the vacuum tube and the junction transistor enabled the 
detection and emission of electromagnetic waves, their generation and amplification, which led to the landmark discoveries of radio, television, modern satellite communication and intercontinental navigation, military and civil radar, thermonuclear fusion and particle acceleration, etc.

A specific segment of the market stems from inventions made up before the $60 \mathrm{~s}$ of the $20^{\text {th }}$ century, meaning vacuum devices for high frequency and high power, that are answering the need for radar amplifiers. The ideas of the magnetron by A.W. Hull (1921), or the klystron by T. Hahn and G.F. Metcalf (1939) or an amplitron by W.C/Brown (1957) were technologies that paved the way for highly efficient microwave power sources, as to meet with the technological requirements of radar techniques. Additionally, due to the invention of traveling wave tubes in 1943 by R. Kompfnera (TWT), it became possible to efficiently amplify a weak microwave signal [7]. Since then, thanks to the forthcoming inventions and developments concerning frequency range, gain and output power level, vacuum devices mostly dominated the market of power amplifiers in the microwave range.

First TWT devices were based on simple, spiral delay lines. At the state of knowledge and level of technology back TWTs were hindered from reaching their inherent potential. Over the following 30 years, their use has been restricted to low-noise amplifiers of microwave signals, or low power amplifiers - from few to several watts. A trigger for further development was the introduction of magnetically hard ferromagnetic materials, based on compounds of rare earth elements and metals $(\mathrm{Sm}-\mathrm{Co})$, which introduced high-density magnetic energy - from 150 $\div 250$ $\mathrm{J} / \mathrm{m}^{3}$. As such, it has led to a radical miniaturization of circuits and increased focusing of a TWT. A stronger focus increased the allowable output power, minimizing losses due to current capture and increased beam current density. Introduced in the 80s of the twentieth century, impregnated, oxide-coated metallic high current density cathodes with allowable emissions up to $10 \mathrm{~A} / \mathrm{cm}^{2}$ allowed the electron beam of the TWT to interact with the spiral giving continuous power output of several hundred watts, up to a range of $10 \mathrm{GHz}$. The problem of heat dissipation from the delay line was solved by mechanically fitting the structure of the delay line (line of coupled resonators) in between ceramic rods, supported by the inner body of the tube. The rods can be pure beryllium oxide $\mathrm{BeO}$ with a coefficient of thermal conductivity equal $265 \mathrm{~W} / \mathrm{mK}$. This leads to an efficient source of microwave power, with further room for development in the emerging markets of space travel, radar and communications.

\section{Travelling Wave Tube (TWT)}

TWTs belong to high power microwave devices, which work in a charge density modulated mode, rather than a current modulated mode. This means that they operate by electron bunching, rather than using a continuous stream of electrons. The key power driving source are moving electrons, thus TWT devices require electron optics and a method to let electrons interact with an electromagnetic field $[8,9]$. TWT devices containing helix delay structures seem to be the most popular. The main components of a helix TWT device are: electron gun, helix slow wave structure (SWS), input and output coupler and an electron collector. A ceramic-metal construction provides exceptional mechanical strength. An electron beam is focused by a periodic permanent magnet (PPM) structure for Brillouin flow behavior of a beam, as it is given in the figure $1[2]$. 


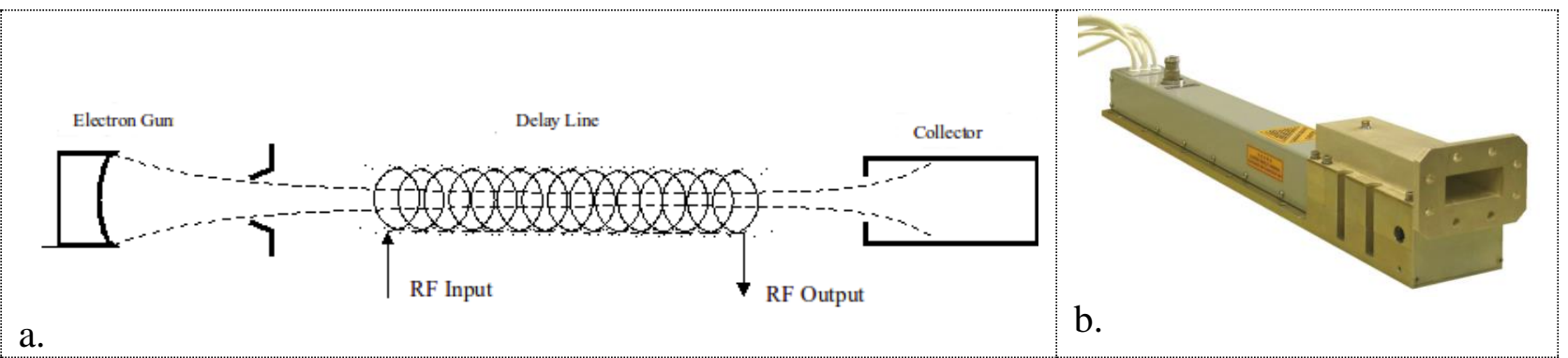

Figure 1: A simplified structure of a TWT device (a) and the final manufactured device (b).

The operating principle of a TWT is based on the interaction of an electromagnetic wave, propagating within a delay line, with the electron beam injected along its long axis of symmetry. The axial electromagnetic field component accelerates and decelerates electrons in a bunch according to their local bunch position - some are accelerated (fast electrons), while others are giving their energy back to the field (slow electrons). As a result, an electron beam density is modulated and the energy extracted from decelerating bunches of electrons is then transferred into the outer circuit. Microwave power generated in the delay line grows exponentially with a distance along its axis of symmetry. In fact the efficiency of the energy transfer of an electron beam into the energy of a microwave signal can be estimated up to $20 \%$ [10].

\section{TWT Thermal Behaviour}

One of the basic problems in operating conditions is thermal behavior of TWT based devices, which directly influences its reliability and performance. As the total energy should be conserved, in case of the analyzed TWT device a detailed structure and an example of the main sources of energy inputs and outputs are given in the figure 2 [11].

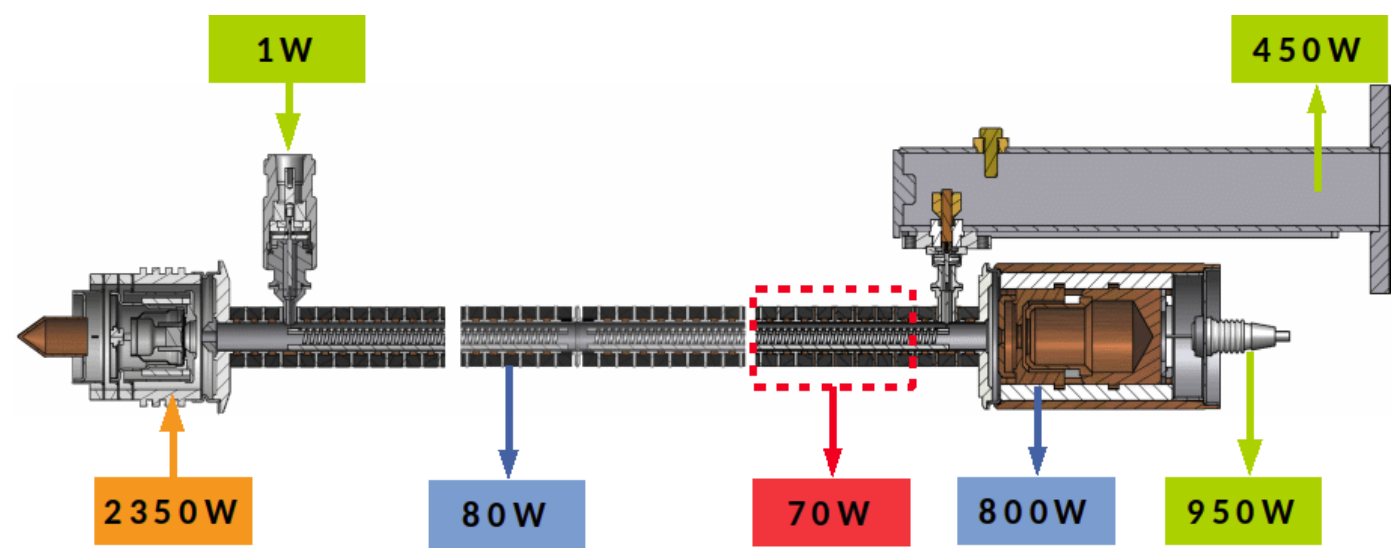

Figure 2: A detailed structure of the analyzed TWT device and an example of a power equilibrium analysis.

As can be concluded from the figure 2, one of the key problems is energy lost in the delay line, which causes a temperature rise at the terminal part of the TWT. In fact, the density of electron beam power can be higher than $1500 \mathrm{~W} / \mathrm{mm}^{2}$. The energy lost in the delay line in the form of Joule heat (e.g. 100W) is mainly due to the following phenomena: 
- power associated to its resistivity $p_{s f}$

- power associated to the electron beam current intercepted by the helix structure through a bombarding phenomenon $p_{s w}$.

These phenomena are the direct cause of a temperature rise in the delay line, and can lead to early failure or performance deterioration of a TWT. In order to avoid an excessive temperature rise, the generated heat energy over the delay line is to be dissipated to the ambient, using structural design of a tube. The heat is mainly dissipated through conduction and convection, as radiation may be neglected due to the typical working temperature of a TWT device, which is below $100^{\circ} \mathrm{C}$.

\section{Analytical Approach}

The microwave power along the axis of a TWT's delay line increases exponentially with its length. One can infer that the delay line's temperature should be highest at its end. In case of an analytical approach, the key problem is to determine the so-called linear density function, $p_{c}$ describing power dissipated along the symmetry axis $z$. The described power loss is due to the interaction between beam current electrons and the periodic structure of the delay line. Such a relationship could be used in numerical analysis to evaluate and predict the temperature distribution in a TWT device. In case of the performed research, such a relationship was evaluated by taking into account a number of assumptions and finally the linear power loss $p_{c}$ along the delay line was assumed to be a sum of two components [9.11]:

$$
p_{c}=p_{s f}+p_{s w}
$$

where $p_{s f}$ refers to power associated with its electrical resistivity while $p_{s w}$ refers to power associated with an interaction of an electron beam current with a helix structure. According the performed detailed analytical calculations, presented by authors in [12], an example of an evaluated linear power density $p_{c}(z)$ dissipated in the delay line, according to the derived analytical formulas, is given in the figure 3 .

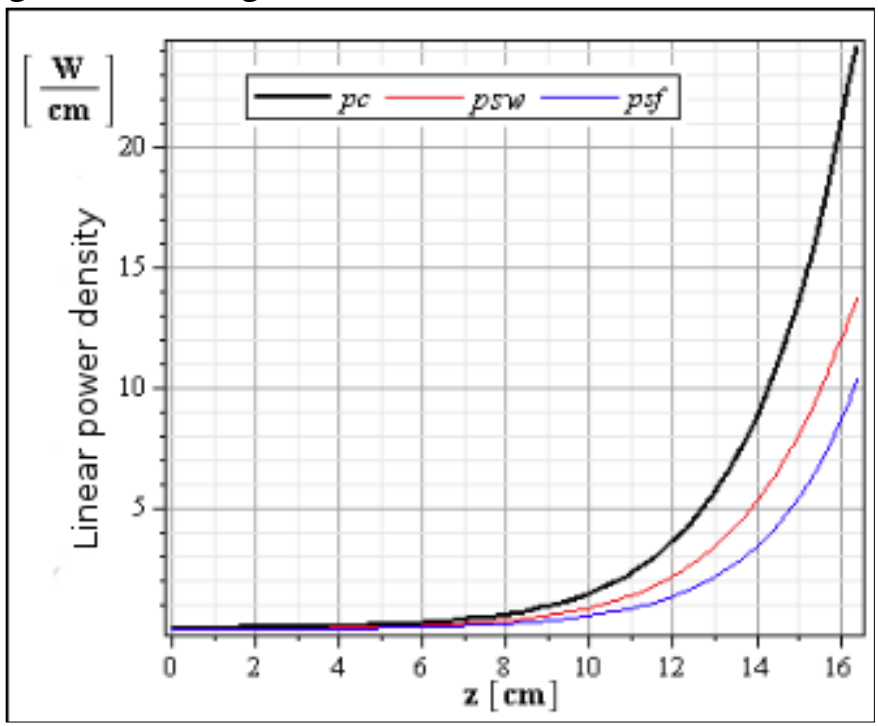

Figure 3: Example of an evaluated linear power density $p_{c}(z)$ dissipated in the delay line according to the derived analytical formulas. 
It should be noted that the analytically evaluated solution was assumed as a reference for the computer simulation of a temperature distribution in TWT device structure and finally validated with the experimental results.

\section{Numerical Analysis}

In case of a numerical modeling of a temperature distribution, according to the presented analytical analysis, it was assumed that only the output section of the TWT device can be taken into account. The computer / numerical model was prepared in ANSYS package v.12. In order to simplify the structure, several assumptions were made and additionally the nonuniform linear power density distribution in the delay line was induced on the segmented helix structure with the total power $P_{n}$ dissipated according to Joule heating phenomenon [12]. Example of an evaluated temperature distribution achieved through numerical analysis of a TWT device due to the assumed linear power dissipation $p_{c}(z)$ is given in the figure 4 .

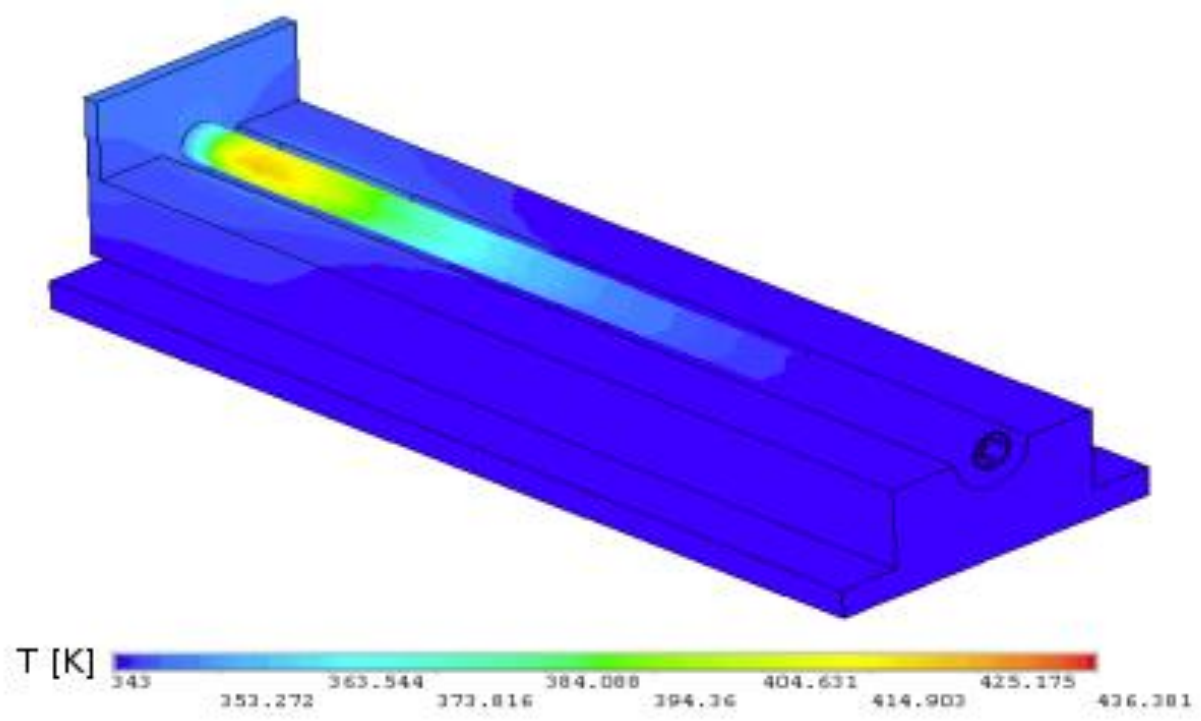

Figure 4: Example of a temperature distribution achieved through numerical analysis of a TWT device due to the assumed linear power dissipation $p_{c}(z)$.

The main goal of the numerical analysis was to compare the temperature distribution of a TWT device $T(z)$ with the given distribution of a linear power dissipation in the delay line $p_{c}(z)$, evaluated by the equation 1. It was assumed that there should be a correlation between the both along $z$ axis, which can be expressed by a formula:

$$
T(z)=k \cdot p_{c}(z)
$$

where $k$ is a proportional coefficient, that does not depend on $z$. In a case of radial heat transfer being dominant, both $T(z)$ and $p_{c}(z)$, should have a similar distribution. This assumption was verified for two different linear power dissipation dependencies - smooth and steep, which is given in the figure 5. In fact, both curves, when normalized, seem to fulfill the equation 2 , except the final region of the delay line, which is mainly due to the collector influence. 


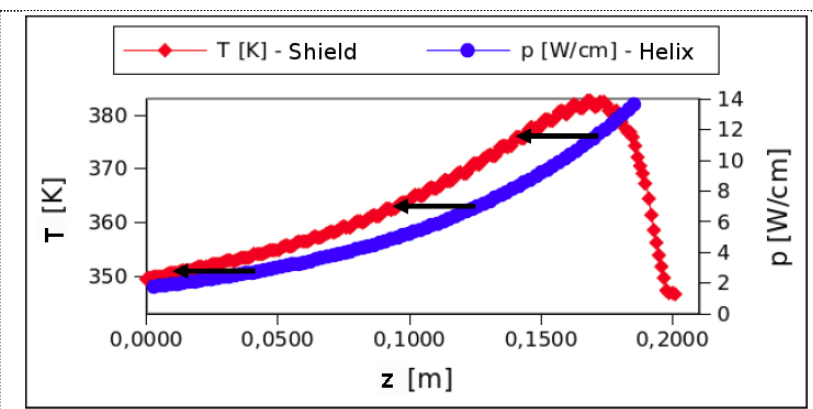

a.

Figure 5: The results of numerical analysis for two different linear power dissipation curves $p_{c}(z)$ (a) smooth (b) steep, where total $p_{c}=107 \mathrm{~W}$.

Finally, it was concluded that by using the presented analytical analysis, numerical simulations, reverse engineering and the evaluated formula 2, it should be possible to assess the linear power dissipation along the delay line.

\section{Experimental Setup and Measurements}

In order to compare the model based on an analytical analysis and numerical simulations, an experimental setup was designed and manufactured, which is shown in the figure 6a. The experimental setup consisted of eight thermocouples bounded to the delay line shield, which were placed between the magnets and the whole system was cooled with water. The objective was to compare the temperature distribution in different parts of the helix TWT assembly, during the working conditions with the analytical and numerical results for corresponding power dissipation. The measurements were done for the selected power supply values $\left(U_{0}=7400 \mathrm{~V}\right.$, $\left.I_{0}=310 \mathrm{~mA}\right)$ and for two microwave input powers $200 \mathrm{~mW}\left(P_{w y}=412 \mathrm{~W}\right)$ and $300 \mathrm{~mW}\left(P_{w y}=425 \mathrm{~W}\right)$. Figure $6 \mathrm{~b}$ contains the comparison of the measured normalized linear power dissipation curves with three different analytical functions, which seem to fulfill the corresponding equations.

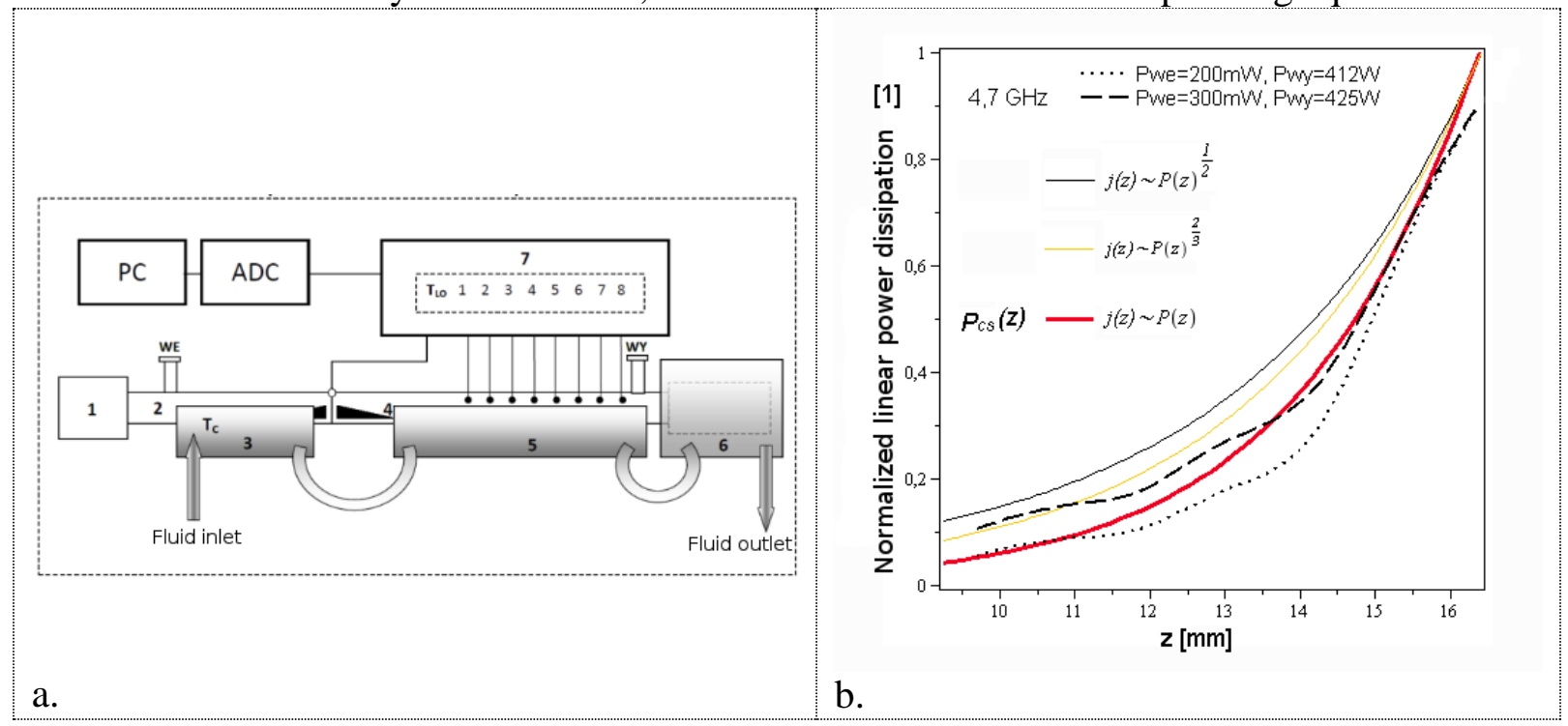

Figure 6: Experimental setup for temperature distribution measurements (a) and a comparison of a measured normalized linear power dissipation in the delay line versus three different analytical dependencies (b). 
According to the presented results, it can be concluded that the best fit of the experimental results with the analytical functions are in the case of a linear power dissipation, that was given by the formula 1. In fact, the formula was derived under the assumption that the density of a beam current intercepted by the delay line $j(z)$, is proportional to the local microwave power $P_{f}(z)[12]$.

\section{Conclusions}

This work describes a thermal analysis of a traveling wave tube device, by a combined analytical, numerical and experimental analysis. The analytical model was focused on an evaluation of the beam current power dissipation and microwave losses along the delay line, which is not uniform and most of the power is accumulated at its terminal part. The analytically evaluated power dissipation function was then used in numerical simulation of a temperature distribution in the working TWT device. The experimental results validated the proposed methodology and through the inverse engineering it was possible to validate the undertaken assumptions on the dependence of a dissipated liner power density along the delay line.

The presented results focused mainly on a problem of the temperature distribution. In fact working TWT devices are exposed to high temperatures, which can influence their reliability. Therefore the presented methodology would be implemented at the design stage and would hopefully lead to better products, which mainly means improved thermal properties and corresponding performance leading finally to more reliable products.

\section{Acknowledgements}

The project was supported by Ministry of Science and Higher Education of Poland as a development project R00 001006.

\section{References}

[1] R.Baker et. al., "Modern Microwave and milimeter-wave power electronics", IEEE Pres.Wiley 2005

[2] R. Gilmour, "Traveling Wave Tubes, Magnetrons, Cross-Field Amplifiers and Gyrotrons", 2011

[3] Wiejak W., Wymysłowski A.; "Thermal analysis of TWT delay line by combined theoretical and numerical approach", 33th International Conference and Exhibition, IMAPS-Poland 2009, Pszczyna, 2009,

[4] Wiejak W., Wymysłowski A.; "Uproszczony analityczny model rozpraszania mocy w linii późniającej lampy fali bieżącej"; Elektronika vol. 3/2010

[5] Robbins, N. R., Christensen, J. A., \& Hallsten, U. R., "Performance and reliability advances in TWT - A high power amplifiers for communications satellites", Military Communications Conference, MILCOM 2005, 1887-1890

[6] Brittain, J. E., "Electrical Engineering Hall of Fame: John A. Fleming", Proceedings of the IEEE 95, Vol. 95, Issue: 1, 2007, pp.: 313-315

[7] R. Kompfner, "The Invention of the Traveling-Wave Tube", San Francisco Press., 1964, p. 30.

[8] Cosslett V.E.; "Introduction to electron optics"; Oxford University Press, London, 1950

[9] Paszkiewicz, B.; "Optyka elektronowa"; PWN, Warszawa, 1960

[10] Gilmour, Jr. A.S.; "Principles Of Traveling Wave Tubes"; Artech House Boston, London, 1994 
[11] Wiejak W.; PhD thesis: "Zastosowanie analitycznych i numerycznych metod wspomagania projektowania do lamp z falą bieżącą", 2013, Wroclaw University of Technology, Poland

[12] Wiejak W., Wymysłowski A.; "Analytical, numerical and experimental approach to thermal analysis and design of a travelling wave tube"; Proceedings of the 16th International Conference on Thermal, Mechanical and Multi-Physics Simulation and Experiments in Microelectronics and Microsystems, EuroSimE 2015; Budapest, Hungary, 2015

[13] JM Weekley, TWTA versus SSPA: A comparison of on-orbit reliability data, IEEE Trans on Electron Dev 2005

[14] W.Q. Lohmeyer, Thesis proposal - Space Environment Impacts on Geostationary Communications Sattelites, 2013, MIT

[15] Behnke L.K.,Montgomery K.L.,Whaley D.R., True R.B., Electron Gun Thermal Design, Analysis and Experimental Validation, 1-4244-0108-9/06/\$20.00 C 2006 IEEE

[16] Czarczyński W., „Lampy mikrofalowe, Wydawnictwa Komunikacji i Łączności, Warszawa 1971

[17] True R., "Tunnel emittance growth in PPM focused TWT's, Techncal Digest, 1985, International Electron Devices Meeting, pp192-195

[18] Gewartowski J.W.,Watson H.A., Principles of Electron Tubes,D.Van Nostrand Company, Inc. 1965

[19] Lucken J.A., Some Aspects of Circuit Power Dissipation in High Power CW Helix TravelingWave Tubes, Part I: General Theory, IEEE Transaction On Electron Devi, Vol. ED-16, No.9, September 1969

[20] Lucken J.A., Some Aspects of Circuit Power Dissipation in High Power CW Helix TravelingWave Tubes, Part I: Scaling Laws, IEEE Transaction On Electron Devi, Vol. ED-16, No.9, pp.821-826, September 1969

[21] Wymysłowski A., Numeryczne metody projektowania termomechanicznego w montażu elektronicznym, Oficyna Wydawnicza Politechniki Wrocławskiej, Wrocław 2007

[22] Shojaefard M.H. and Goudarzi K., The Numerical Estimation of Thermal Contact Resistance in Contacting Surfaces, American Journal of Applied Sciences 5 (11): 1566-1571, 2008

*Corresponding author.

E-mail address: artur.wymyslowski@pwr.edu.pl 